\title{
Rational alloying of secondary and aromatic ammonium cations in a metal-halide perovskite toward crystal-array photodetection
}

\author{
Wuqian Guo ${ }^{1,2}$, Huaixi Chen ${ }^{1}$, Xitao Liu ${ }^{1}$, Yu Ma ${ }^{1}$, Jiaqi Wang ${ }^{1}$, Yi Liu ${ }^{1,2}$, Shiguo Han ${ }^{1,2}$, Haojie Xu ${ }^{1,2}$, \\ Junhua Luo $^{1}$ and Zhihua Sun ${ }^{1,3^{*}}$
}

\begin{abstract}
Two-dimensional (2D) hybrid perovskites with the Ruddlesden-Popper lattice $\left(\mathrm{A}^{\prime}\right)_{2}(\mathrm{~A})_{n-1} \mathbf{M}_{n} \mathbf{X}_{3 n+1}$ are emerging as the promising optoelectronic candidates, both the inorganic and organic ingredients of which can be tailored to modulate the physical properties. Nevertheless, there is a scarcity of 2D multilayered motifs with the A-site large-size cations occupying perovskite cavities. Here, by rational mixedcation alloying, we present a new $2 \mathrm{D}$ hybrid perovskite, (4-TFBMA) (DMA) $_{2} \mathrm{Db}_{2} \mathrm{I}_{7}(1)$, in which the secondary cation of $\mathrm{CH}_{3} \mathrm{NH}_{2} \mathrm{CH}_{3}{ }^{+}$(DMA) is located inside the perovskite cage while the aromatic 4-(trifluoromethyl)benzylammonium (4-TFBMA) cation acts as a spacer moiety. Benefiting from the quantum structure of alternating organic spacers and inorganic networks, crystal-array detectors of 1 show fascinating in-plane photodetection responses of large detectivity $(\sim 2.95 \times$ $10^{12}$ Jones) and responsivity $\left(\sim 1.97 \mathrm{~A} \mathrm{~W}^{-1}\right)$, comparable to those of some inorganic $2 \mathrm{D}$ counterparts. In addition, a fast response rate $(\sim 264 \mu s)$ and a low dark current are also realized, related to the high crystalline quality and suppression of the hopping barrier due to the insulating organic spacing layers. This result sheds light on the further exploration of new 2D hybrid perovskites toward high-performance photodetector applications.
\end{abstract}

Keywords: two-dimensional, hybrid perovskites, photodetection, array

\section{INTRODUCTION}

Two-dimensional (2D) hybrid perovskites with the RuddlesdenPopper phase have recently received persistent attention due to their fascinating photoelectric characteristics, including low trap density, high optical absorption, and high carrier mobility. These unique characteristics make them a promising family of candidates for optoelectronic device applications including light-emitting diodes, solar cells, and photodetectors [1-10]. Generally, the members of this class adopt a basic formula of $\left(\mathrm{A}^{\prime}\right)_{2}(\mathrm{~A})_{n-1} \mathrm{M}_{n} \mathrm{X}_{3 n+1}$, where $\mathrm{A}^{\prime}$ is an organic "spacer" cation between inorganic perovskite sheets, $\mathrm{A}$ is a "perovskiter" cation inside the $\mathrm{MX}_{6}$ octahedral cavity, $\mathrm{M}$ is a divalent metal cation and $\mathrm{X}$ is a halide. From a structural perspective, the abundant incorporation of $\mathrm{A}$ and $\mathrm{A}^{\prime}$ cations into $2 \mathrm{D}$ hybrid perovskites endows them with infinite structural diversity, opening up a new pathway to largely enrich this family toward high-performance optoelectronic devices [11-14]. Among them, the choice of the $\mathrm{A}^{\prime}$-site spacing cation is not restricted by the tolerance factor, which allows for the accommodation of large components of alkylamines and aromatic amines [15]. In contrast, only a few small cations (e.g., $\mathrm{Cs}^{+}, \mathrm{CH}_{3} \mathrm{NH}_{3}^{+}\left(\mathrm{MA}^{+}\right), \mathrm{NH}_{2}(\mathrm{CH}) \mathrm{NH}_{2}^{+}\left(\mathrm{FA}^{+}\right)$ and $\left.\mathrm{C}_{2} \mathrm{H}_{5} \mathrm{NH}_{3}{ }^{+}\left(\mathrm{EA}^{+}\right)\right)$can be situated in the octahedral cavity as "perovskiter" components [16-19]. The length and coordination preference should fulfil the strict limitation of the Goldschmidt's tolerance factor concept [20]. Notably, some 2D RuddlesdenPopper materials containing large-radius cations in metal-halide perovskite cavities were recently obtained, such as guanidine $(\sim 278 \mathrm{pm})$ and dimethylamine (DMA, 272 pm) [21-23]. Despite the attempts to explore new candidates, studies on their physical attributes and potential optoelectronic applications remain quite scarce. It is of significance to design new 2D hybrid perovskites by broadening the new "perovskiter" and spacer choices, which is also crucial to assembling high-performance optoelectronic devices.

Chemical alloying of organic cations is an effective strategy to form new structural motifs and allows the modulation of physical properties. As a subclass of $\mathrm{AMX}_{3}$ cubic perovskites, different types of 2D layered frameworks can be built by mixedcation alloying, depending on the length and charge state of spacing moieties [24]. This flexibility has been well illustrated by a series of hybrids containing alkyl ammonium cations, such as $\left(\mathrm{CH}_{3}\left(\mathrm{CH}_{2}\right)_{3} \mathrm{NH}_{3}\right)_{2}\left(\mathrm{CH}_{3} \mathrm{CH}_{2} \mathrm{NH}_{3}\right)_{2} \mathrm{~Pb}_{3} \mathrm{I}_{10}$ and $\left(\mathrm{CH}_{3}\left(\mathrm{CH}_{2}\right)_{5} \mathrm{NH}_{3}\right)_{2}-$ $\left(\mathrm{CH}_{3} \mathrm{NH}_{3}\right)_{n-1} \mathrm{~Pb}_{n} \mathrm{I}_{3 n+1}[25,26]$. Particularly, it is facile to modulate the distance between adjacent perovskite sheets of 2D Ruddlesden-Popper lattices, which affects the barrier thickness of their underlying quantum wells. The band edge states, insulated by organic spacing layers, also boost the fast dissociation of photoinduced electron-hole pairs and the electron mobility [24,27]. These unique attributes endow 2D hybrid perovskites with great promise for high-performance photodetection. The current mainstream is still dominated by small-size cations (e.g., $\mathrm{MA}^{+}, \mathrm{EA}^{+}$and $\mathrm{FA}^{+}$) situated in the octahedral cages as a "perovskiter". In this context, the alloying of secondary and aromatic ammonium cations will not only enrich the materials of this $2 \mathrm{D}$ family but also enable implementation of their high-performance photodetectors.

Herein, by rational mixed-cation alloying, we successfully design a new 2D Ruddlesden-Popper hybrid perovskite,

\footnotetext{
${ }^{1}$ Fujian Institute of Research on the Structure of Matter, Chinese Academy of Sciences, Fuzhou 350002, China

${ }^{2}$ University of Chinese Academy of Sciences, Chinese Academy of Sciences, Beijing 100039, China

${ }^{3}$ Fujian Science \& Technology Innovation Laboratory for Optoelectronic Information of China, Fuzhou 350108, China

* Corresponding author (email: sunzhihua@fjirsm.ac.cn)
} 


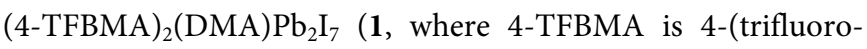
methyl)benzylammonium)). As expected, it adopts a typical 2D topology of an alternaing arrangement of inorganic perovskite bilayers and organic spacers, resembling that of quantum wells. It is worth noting that crystal-based array photodetectors of $\mathbf{1}$ display attractive performances, including high detectivity $\left(\sim 2.95 \times 10^{12}\right.$ Jones), a responsivity of $\sim 1.97 \mathrm{~A} \mathrm{~W}^{-1}$ and low dark current $\left(\sim 9.63 \times 10^{-11} \mathrm{~A}\right)$. This work emphasizes the potential of $\mathbf{1}$ in the field of photodetection, and paves the way for designing new members for optoelectronic applications.

\section{EXPERIMENTAL SECTION}

Compound 1 crystallizes in a concentrated HI solution consisting of $\left[\mathrm{Pb}\left(\mathrm{CH}_{3} \mathrm{COO}\right)_{2} \cdot 3 \mathrm{H}_{2} \mathrm{O}\right](5 \mathrm{mmol}, 1.89 \mathrm{~g}), 4$-TFBMA ( $5 \mathrm{mmol}, 0.88 \mathrm{~g})$, and DMA $(2.5 \mathrm{mmol}, 0.12 \mathrm{~g})$. Bright red crystals of 1 were synthesized via temperature cooling at a rate of $1^{\circ} \mathrm{C} \mathrm{day}^{-1}$. X-ray diffraction (XRD) of the crystals was performed on a Bruker D8 Quesr/Venture diffractometer with Mo Ka radiation $(\lambda=0.77 \AA)$. We used the direct methods to solve the room-temperature structure and further refined it via fullmatrix least-squares techniques on the basis of $F^{2}$ utilizing the SHELXS-97 software package.

Planar array photodetectors were fabricated using high-quality crystal wafers of $\mathbf{1}$. The Au electrodes filtered by a copper mesh with a square form were thermally overlaid on a wafer surface via a sputtering method. The length of the Au electrode was $260 \mu \mathrm{m}$ and the distance between adjacent electrodes was $30 \mu \mathrm{m}$. The photoelectric properties were measured by a Keithley $6517 \mathrm{~B}$ analyzer, and wavelength-dependent measurements were accomplished by virtue of a battery of filters. The variabletemperature conductivity was derived from the imaginary part of the dielectric measurement results. The response rate was documented via a high-speed Tektronix MDO3014 Oscilloscope.

\section{RESULTS AND DISCUSSION}

Generally, Goldschmidt's tolerance equation of $\alpha=\left(r_{\mathrm{A}}+r_{\mathrm{X}}\right) \times$ $\left[\sqrt{2}\left(r_{M}+r_{X}\right)\right]$ ( $r$ denotes the effective radius of the ions for ammonium cation $\mathrm{A}$, metal $\mathrm{M}$ and anion $\mathrm{X}$ ) indicates that the $\alpha$ value should be within the range of $0.8-1.0$ for most $3 \mathrm{D}$ perovskite structures (e.g., $\mathrm{MAPbI}_{3}, \sim 0.912$ ) [28]. In contrast, it is almost impossible to form the similar $3 \mathrm{D}$ structure containing the $\mathrm{DMA}^{+}$cation $(r=272 \mathrm{pm})$, due to the constraint arising from the tolerance factor $(\alpha=1.03)$. As expected, distinct from the 3D structure of $\mathrm{MAPbI}_{3}, \mathrm{DMAPbI}_{3}$ extends the basic architecture in the 1D perovskite model [29]. Nevertheless, rational mixed-cation alloying of this secondary cation and other alkyl/aromatic cations could form 2D multilayered hybrid perovskite structures, which is an effective approach to permit large-size cations to enter the perovskite cavity (Scheme 1). Simultaneously, aromatic cations containing free and polarizable $\pi$-electrons can improve the optoelectronic performance by reducing the exciton binding energy [30-32]. Inspired by this strategy, we successfully synthesized compound $\mathbf{1}$ by alloying aromatic ammonium and the secondary $\mathrm{DMA}^{+}$cation.

Crystals of $\mathbf{1}$ were synthesized by controlling the stoichiometric ratio in concentrated HI solutions. Subsequently, flake crystals were grown by the temperature cooling method, and the powder XRD pattern collected at $298 \mathrm{~K}$ confirms the purity of the as-grown crystals, in agreement with the simulated patterns of 2D bilayer perovskites (Figs S1 and S2). Structural analysis shows that $\mathbf{1}$ is a typical Ruddlesden-Popper hybrid perovskite that crystallized in the centrosymmetric space group $P 2_{1} / c$, with unit cell parameters of $a=23.613 \AA, b=8.962 \AA, c=8.884 \AA$ and $\beta=96.071^{\circ}$ (at $273 \mathrm{~K}$, Table S1). Its bilayered hybrid perovskite motif is similar to a sandwich-like structure (Fig. 1a), consisting of inorganic sheets of corner-sharing $\mathrm{PbI}_{6}$ octahedra and intercalated spacing layers of organic $4-\mathrm{TFBMA}^{+}$cations. The $\mathrm{PbI}_{6}$ octahedron shows a slight distortion as verified by the inhomogeneous $\mathrm{Pb}-\mathrm{I}$ bond lengths (Table S2). The multitudinous I$\mathrm{Pb}-\mathrm{I}$ bond edges also reveal the irregular architectural geometry (Table S3). Compared with those of $\mathrm{MAPbI}_{3}$, the deformation of the $\mathrm{I}-\mathrm{Pb}-\mathrm{I}$ bond angles and the difference in the $\mathrm{Pb}-\mathrm{I}$ bond lengths in $\mathbf{1}$ lead to an increasing in the cavity volume formed by the octahedra. As shown in Fig. 1b, the volume composed of eight adjacent $\mathrm{PbI}_{6}$ octahedra for 1 is evaluated to be $\sim 262.5 \AA^{3}$, which is larger than that of $\mathrm{MAPbI}_{3}\left(\sim 248.6 \AA^{3}\right)$. This distortion affords a large space to accommodate the organic $\mathrm{DMA}^{+}$cation

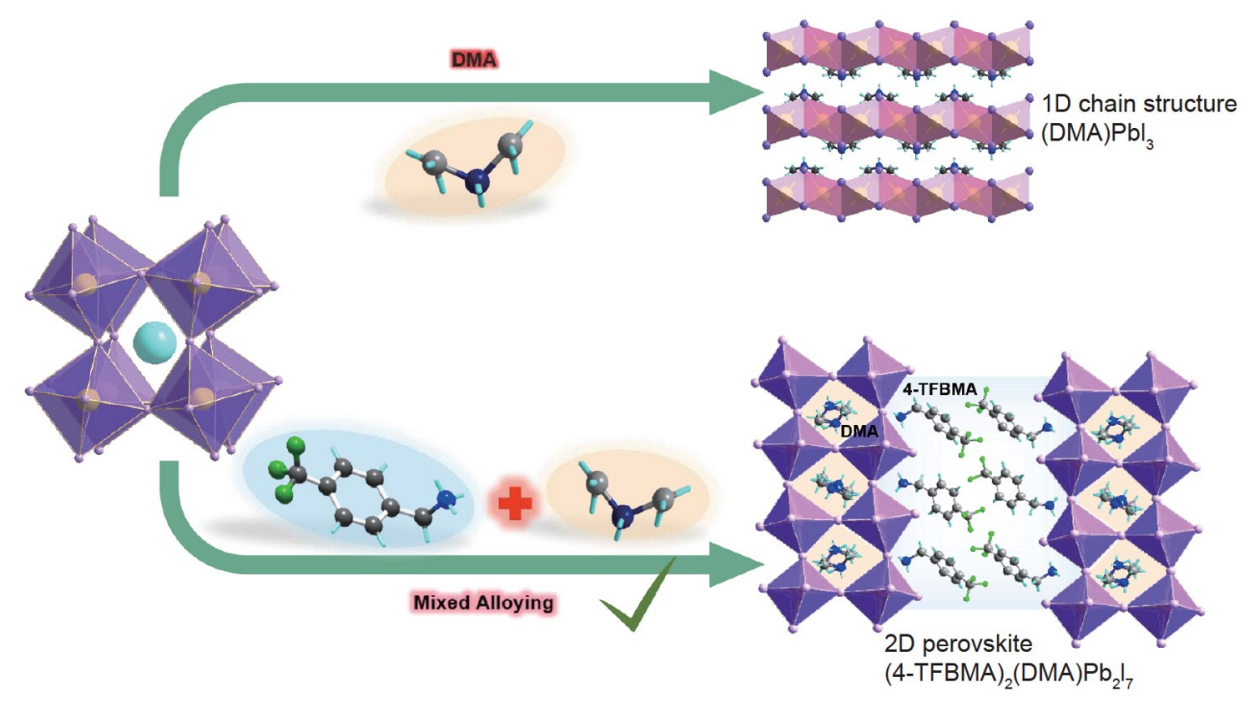

Scheme 1 The tailored design of 1 through mixed-cation alloying. Due to the constraint arising from the tolerance factor, only a 1D chain-like framework is formed for (DMA) $\mathrm{PbI}_{3}$ instead of a 3D perovskite cage. Mixed-cation alloying leads to the 2D bilayered perovskite motif for $\mathbf{1}$. 

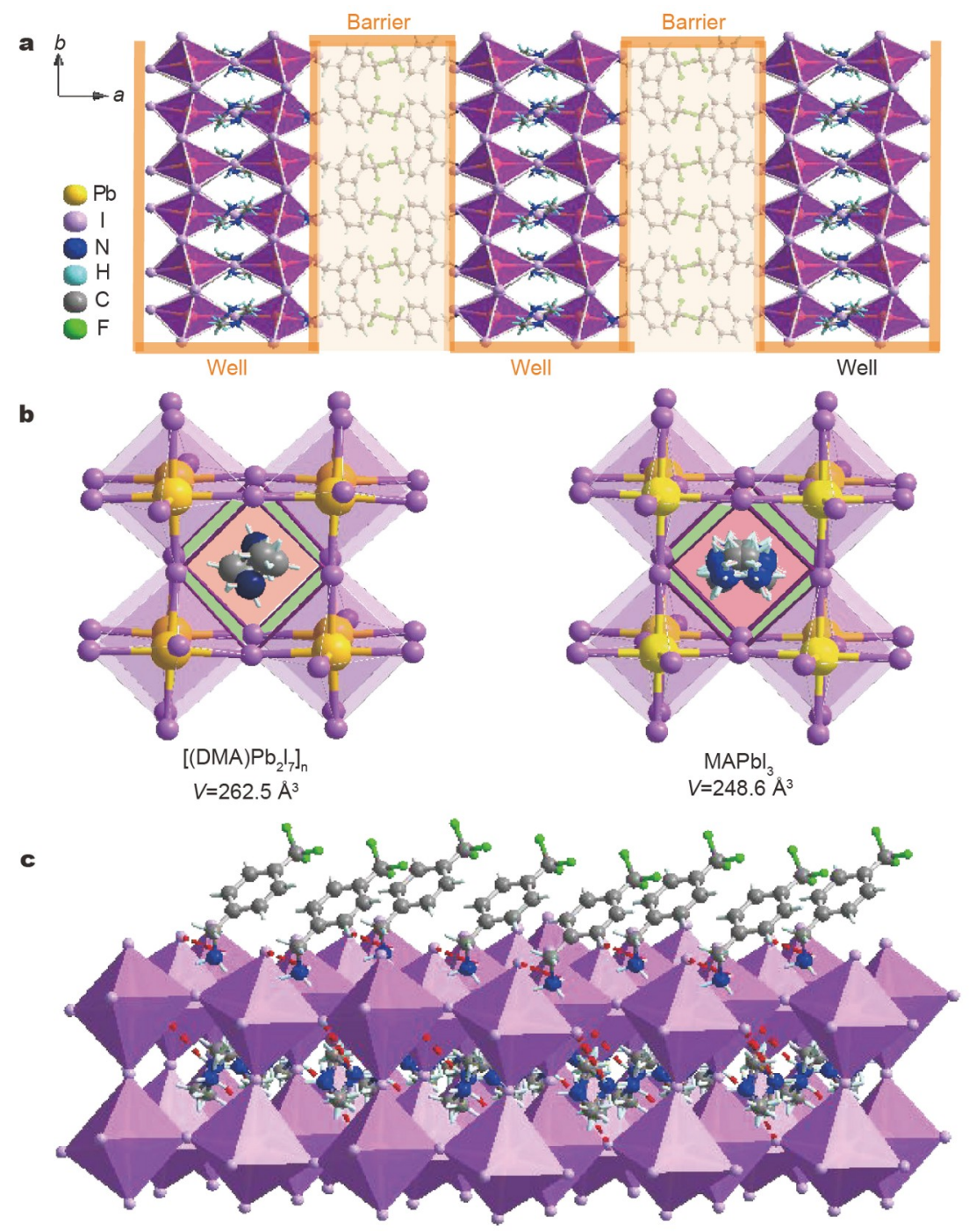

Figure 1 (a) Illustration of the 2D quantum well structure of 1 . (b) Comparison of the cage volumes of basic perovskite frameworks of 1 and MAPbI ${ }_{3}$. (c) Strong $\mathrm{N}-\mathrm{H} \cdots \mathrm{I}$ hydrogen bonds between the organic cations and $\mathrm{PbI}_{6}$ octahedra.

as the "perovskiter". The organic $\mathrm{DMA}^{+}$cation is closely linked to the $\mathrm{PbI}_{6}$ octahedra of the perovskite framework by powerful $\mathrm{N}-\mathrm{H}$...I hydrogen bonds (Table S4). Meanwhile, the spacing layers of organic $4-\mathrm{TFBMA}^{+}$cations are distributed between the contiguous inorganic sheets, interacting by strong $\mathrm{N}-\mathrm{H} \cdots \mathrm{I}$ hydrogen bonds (Fig. 1c). Along the $a$-axis, the alternating arrangement of organic spacer bilayers and inorganic sheets forms a 2D quantum-well configuration, where both electrons and holes are confined within the well, leading to enhancement of radiative recombination and strong binding energies for the exciton [33-35].

The optical absorption feature is a crucial attribute for the photodetector applications. Fig. 2a shows the optical absorption spectrum in the ultraviolet (UV)-visible range, in which the distinct absorption edge is located at $\sim 620 \mathrm{~nm}$. The optical bandgap $\left(E_{\mathrm{g}}\right)$ of $\sim 2.03 \mathrm{eV}$ is estimated by extrapolating the highenergy edge to the energy axis. This figure of merit is comparable to that of some typical lead-iodinated hybrid perovskites, such as $\left(\mathrm{CH}_{3}\left(\mathrm{CH}_{2}\right)_{3} \mathrm{NH}_{3}\right)_{2}\left(\mathrm{CH}_{3} \mathrm{NH}_{3}\right)_{2} \mathrm{~Pb}_{3} \mathrm{I}_{10} \quad(\sim 2.01 \mathrm{eV})$ and $\left(\mathrm{CH}_{3}\left(\mathrm{CH}_{2}\right)_{4} \mathrm{NH}_{3}\right)_{2}\left(\mathrm{C}\left(\mathrm{NH}_{2}\right)_{3}\right) \mathrm{Pb}_{2} \mathrm{I}_{7}(\sim 2.02 \mathrm{eV})$ [36,37]. To further explore the microscopic origin of its semiconducting behavior, we calculated the electronic band structure of $\mathbf{1}$ by the density functional theory (DFT) method. As shown in Fig. 2b, calculations on the band alignment reveal that significant contribution from the perovskite framework to the natural Type-I quantum wells. The calculated electronic bandgap is $2.20 \mathrm{eV}$, which is basically consistent with our experimental value. The valence band maximum and conduction band minimum of $\mathbf{1}$ are situated at point $\mathrm{G}$, disclosing its direct bandgap feature. Analyses of the partial density of states (PDOS) spectrum show that the inorganic networks play a decisive role in its energy band gap (Fig. S3). The electronic band edges are decided by the $\mathrm{Pb}-\mathrm{I}$ bond in the octahedral unit. Specifically, the anti-bonding combination of the $\mathrm{Pb} 6 \mathrm{~s}$ and $\mathrm{I} 5 \mathrm{p}$ orbitals mainly give rise to the valence band maximum, and anti-bonding combination between the $\mathrm{Pb} 6 \mathrm{p}$ and I $5 \mathrm{p}$ orbitals mainly dominate the conduction band minimum [38]. This result can also be observed in the highest occupied molecular orbital (HOMO) and the lowest unoccupied molecular orbital (LUMO) (Fig. 2c). Calculation of the band alignment shows that the instability of $n s^{2}$ lone pairs of the $\mathrm{Pb}^{2+}$ cation results in the high mobilities of photocarriers in accord with the quantum confinement of electrons and holes in 

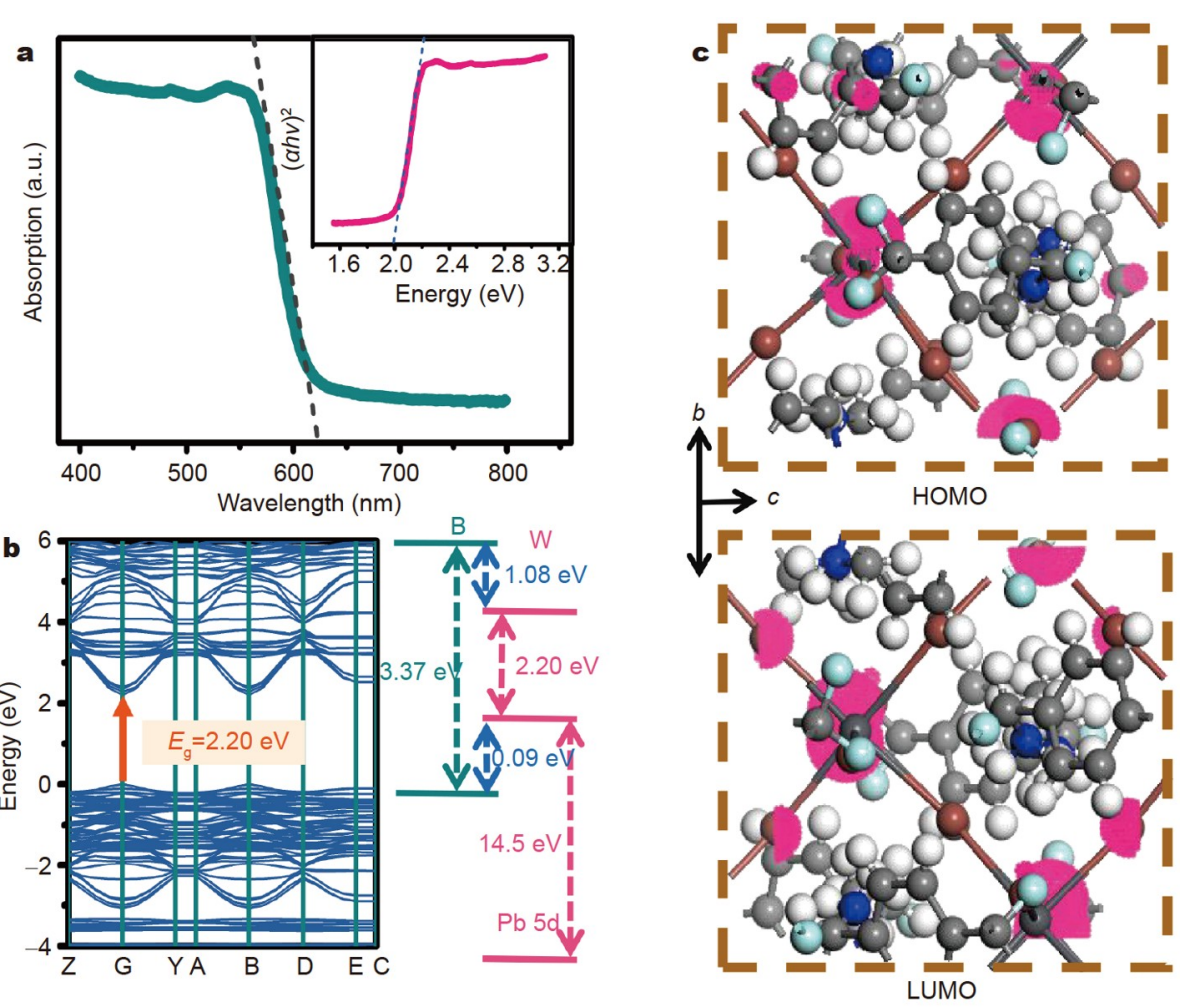

Figure 2 (a) UV-vis absorption spectra of 1. Inset: calculation results of the bandgap using the Tauc method. (b) Electronic band structure and band alignment of 1. (c) Frontier molecular orbitals.
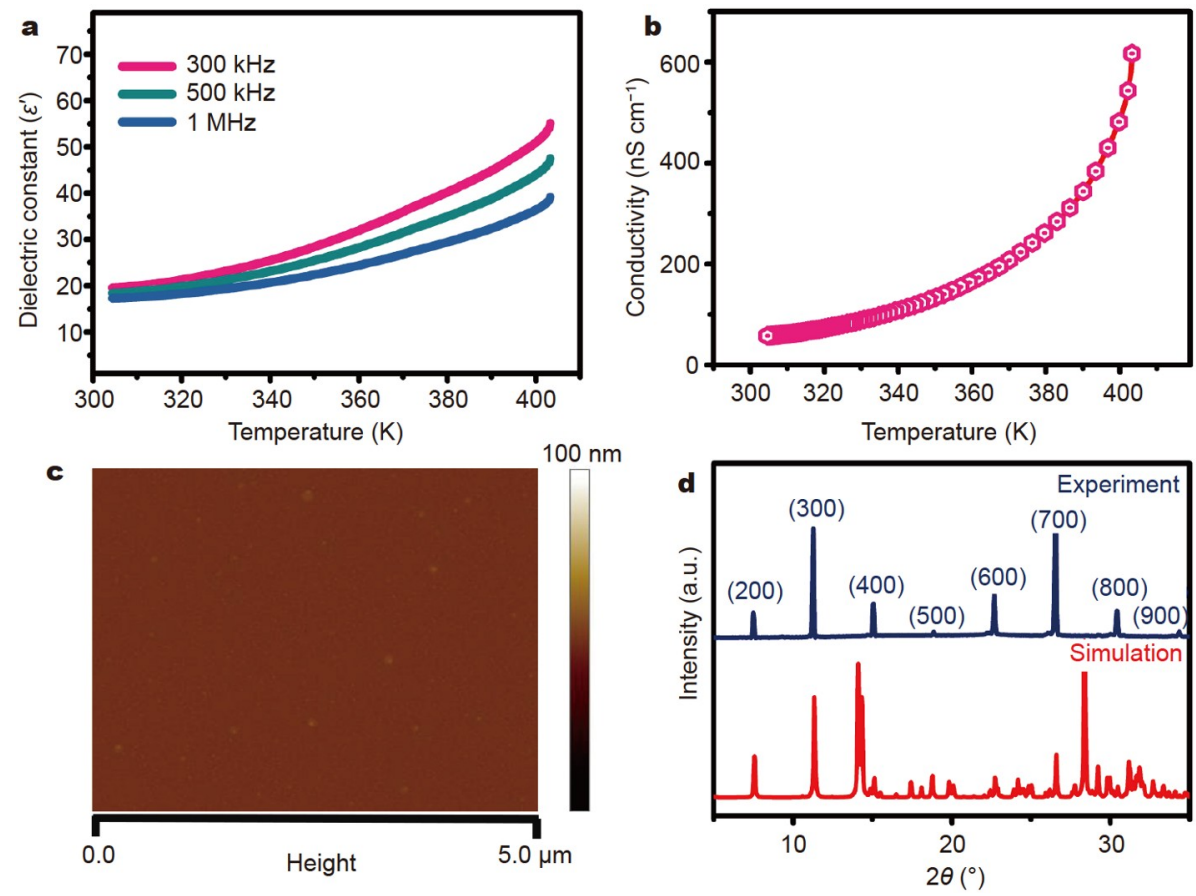

Figure 3 (a) Variable-temperature dielectric permittivity and (b) conductivity obtained from a single-crystal sample of $\mathbf{1}$. (c) Surface morphology measured by AFM. (d) XRD patterns of the crystal wafer.

the inorganic sheet composed of $\mathrm{PbI}_{6}$ octahedra [18,39].

The temperature-dependent permittivity and conductivity of 1 exhibit a positive slope with increasing temperature, suggesting its semiconductor characteristics (Fig. 3a, b). Subsequently, we performed atomic force microscopy (AFM) measurements of the crystal surface of the wafer. The visualized morphology patterns display few surface defects and grain boundaries, indicating the single crystal nature of the wafer (Fig. 3c). Scanning electron 
microscopy (SEM) images corroborate this fact (Fig. S4). XRD patterns of the crystal reveal partial diffraction peaks corresponding to indices of $\left(\begin{array}{lll}2 & 0 & 0\end{array}\right)$ to $\left(\begin{array}{l}9 \\ 0\end{array}\right)$, which suggests that the crystal wafers of 1 have a preferred oriented arrangement parallel to the $b c$ plane direction (Fig. 3d). Such advantages prompted us to assemble a crystal-based photodetector, and evaluate the potential of $\mathbf{1}$ for high-performance photodetection.

Planar array photodetectors with an Au electrode were constructed on the smooth surface of high-quality crystal wafers of 1, and the effective area between neighboring poles was $\sim 6.9 \times$ $10^{-5} \mathrm{~cm}^{2}$ (Fig. 4a). The current-voltage $(I-V)$ properties were characterized under the same incident light intensity, and the photoresponse of $\mathbf{1}$ at different wavelengths is depicted in Fig. $4 \mathrm{~b}$. The result shows that our detector is sensitive to visiblelight over a wide range, with the maximum photocurrent $\left(I_{\text {photo }}\right)$ observed at approximately $550 \mathrm{~nm}$. This wavelength-dependent photoresponse has been observed in other $2 \mathrm{D}$ hybrid perovskites, such as $\left(\mathrm{C}_{5} \mathrm{H}_{11} \mathrm{NH}_{3}\right)_{2}\left(\mathrm{CH}_{3} \mathrm{NH}_{2} \mathrm{CH}_{3}\right) \mathrm{Pb}_{2} \mathrm{I}_{7}$ [40]. Therefore, we attempted to characterize our crystal-based photodetectors at this wavelength to obtain the optimum photo- sensitivity behavior. According to the photoexcitation effect, a higher incident light power can enhance the carrier concentration to realize a better optical response. In view of the highquality crystal of $\mathbf{1}$, the dark current $\left(I_{\text {dark }}\right)$ of our array device is $9.63 \times 10^{-11} \mathrm{~A}$, which is comparable to that of some reported perovskite-based optoelectronic devices, such as $\left(\mathrm{C}_{6} \mathrm{H}_{5} \mathrm{CH}_{2} \mathrm{CH}_{2}\right.$ $\left.\mathrm{NH}_{2}\right)_{2} \mathrm{SnI}_{4}$ microsheets and $\left(\mathrm{C}_{4} \mathrm{H}_{9} \mathrm{NH}_{3}\right)_{2}\left(\mathrm{CH}_{3} \mathrm{NH}_{3}\right) \mathrm{Pb}_{2} \mathrm{I}_{7}[41,42]$. Under illumination, the dramatic variation in the photocurrent with the incident illumination power and bias voltage is revealed in Fig. 4c. $I_{\text {photo }}$ shows a significant increase to $\sim 5.67 \times 10^{-8} \mathrm{~A}$ and the switching ratio $\mathrm{SR}=\left(I_{\text {photo }}-I_{\text {dark }}\right) / I_{\text {dark }}$ is calculated to be $\sim 6 \times 10^{2}$ (at $V_{\text {bias }}=10 \mathrm{~V}, \sim 32.4 \mathrm{~mW} \mathrm{~cm}^{-2}$ ), This figure of merit is comparable to that of some other counterparts, e.g., (TMHD)$\mathrm{BiBr}_{5}(\mathrm{TMHD}=\mathrm{N}, \mathrm{N}, \mathrm{N}, \mathrm{N}$-tetramethyl-1,6-hexanediammonium) [43]. Meanwhile, it also has favorable working stability (Fig. S5). All of these properties indicate its potential for application in the field of photodetection.

Because of the above physical attributes, we further assessed the capability of 1 to detect weak light, including the responsivity $(R)$ and detectivity $\left(D^{*}\right)$, which are vital parameters for the
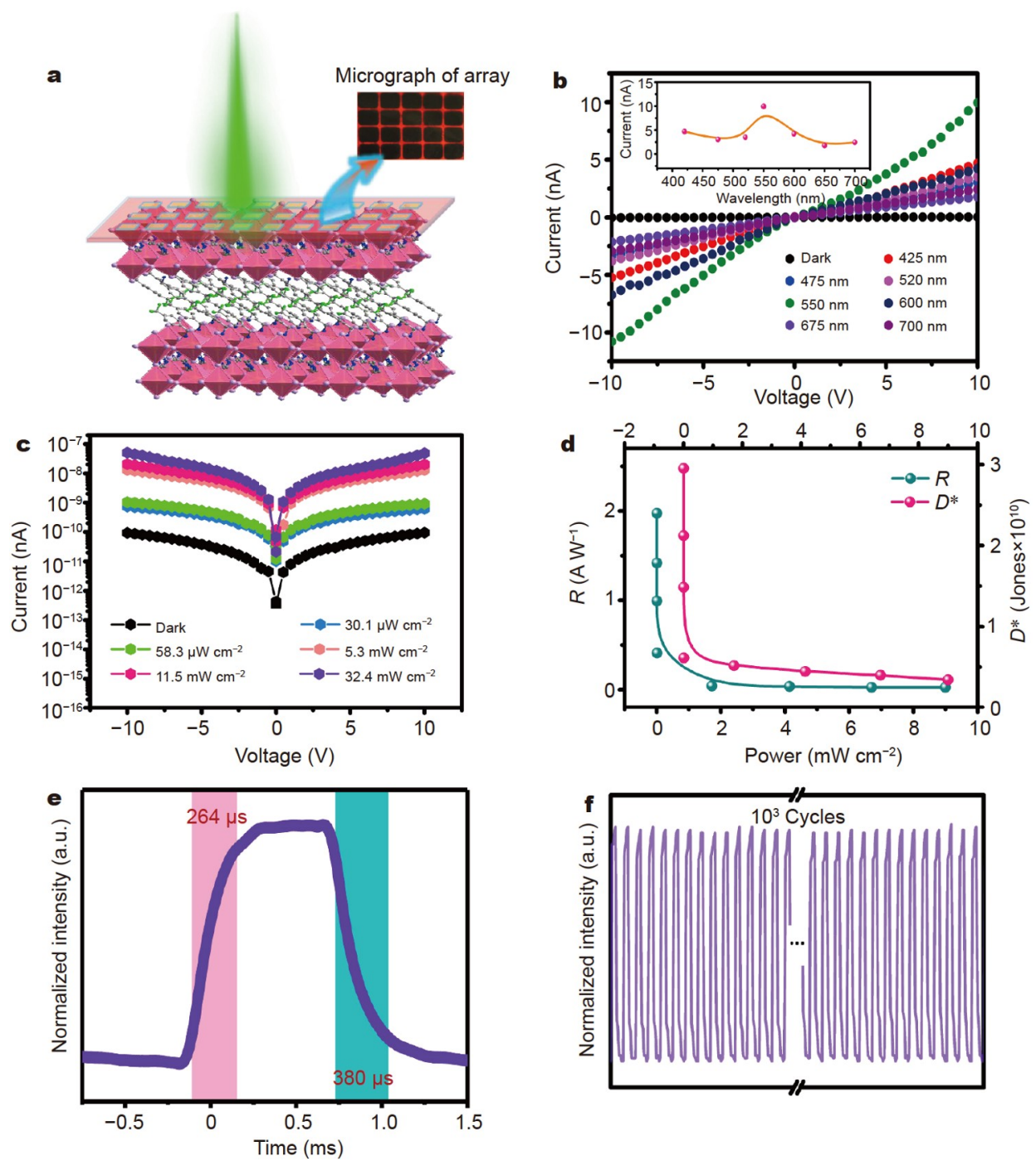

Figure 4 (a) Schematic structure of the planar array photodetector. (b) Photoresponse of 1 under different wavelengths from 425 to $700 \mathrm{~nm}$. Inset: wavelength dependence of $I-V$ curves. (c) The $I_{\text {photo }}$ and $I_{\text {dark }}$ measured under the different illumination intensities. (d) $R$ and $D^{*}$ values as a function of incident light power under different voltages. (e) Photoresponse time of 1. (f) Long-term repeated photoswitching cycles. 
photoelectric device. Considering that the dark current is the primary factor causing noise, $R$ is defined as the ratio of the photocurrent to the incident light intensity, $R=I_{\text {photo }} /\left(P_{0} A\right)$, and $D^{*}$ can be expressed as $D^{*}=I_{\text {photo }} A^{1 / 2} /\left[P_{0} \times\left(2 e J_{\text {dark }}\right)^{1 / 2}\right]$, where $P_{0}$ is the irradiation power density, $A$ denotes the valid area of the photodetector and $e$ denotes the unit charge. The $R$ and $D^{*}$ calculated under different light power densities are presented in Fig. $4 \mathrm{~d}$. As the incident light intensity decreases, the $R$ and $D^{*}$ values rapidly increase. In particular, under an illumination power of $\sim 5.84 \mu \mathrm{A} \mathrm{cm}^{-2}$, the estimated $R$ value is approximately $1.97 \mathrm{~A} \mathrm{~W}^{-1}$, which is higher than that of some photodetectors based on hybrid perovskites, such as the $\mathrm{MAPbI}_{3}$ crystal $\left(\sim 0.5 \mathrm{~A} \mathrm{~W}^{-1}\right) \quad$ and $\quad\left(\mathrm{C}_{5} \mathrm{H}_{11} \mathrm{NH}_{3}\right)_{2}\left(\mathrm{CH}_{3} \mathrm{NH}_{3}\right) \mathrm{Pb}_{2} \mathrm{I}_{7} \quad$ crystal $\left(\sim 3.8 \mathrm{~mA} \mathrm{~W}^{-1}\right)[44,45]$. The related $D^{*}$ value is calculated to be $2.95 \times 10^{12}$ Jones, which is much higher than that of some reported detectors, such as the $\left(\mathrm{C}_{4} \mathrm{H}_{9} \mathrm{NH}_{3}\right)_{2}(\mathrm{MA})_{2} \mathrm{~Pb}_{3} \mathrm{Br}_{10}$ crystal $\left(3.6 \times 10^{10}\right.$ Jones $)$ and $\mathrm{MoS}_{2}$-Si $\left(2.1 \times 10^{10}\right.$ Jones $)$, and almost comparable to that of commercial silicon detectors $\left(\sim 4 \times 10^{12}\right.$ Jones) $[17,46]$. The device performances of some 2D hybrid perovskites are listed in Table S5. These prominent properties are closely related to the high quality of the single crystals, the miniaturization of the detection area and the enhanced photocurrent magnified by the array architecture. The photoresponse time $(\tau)$ is another important parameter for photodetectors. As shown in Fig. $4 \mathrm{e}$, the rise $\left(\tau_{\text {rise }}\right)$ and fall $\left(\tau_{\text {fall }}\right)$ response times reach $\sim 264$ and $380 \mu$ s, respectively, which are faster than those of some hybrid perovskite-integrated detectors such as $\mathrm{FAPbI}_{3}(12.4 \mathrm{~ms})$ [46]. Meanwhile, the cycling test of our photodetector shows that the photocurrent does not significantly attenuate after repeated on/off light switching, disclosing the notable fatigue resistance merit of the detector (Fig. 4f). In addition, $\mathbf{1}$ has excellent thermal stability and phase stability (Figs S6 and S7). These advantageous features for planar arrays of $\mathbf{1}$ afford tremendous potential in high-speed photodetection.

\section{CONCLUSIONS}

In summary, by rationally alloying the secondary and aromatic ammonium cations, we realized a new $2 \mathrm{D}$ hybrid perovskite, $\mathbf{1}$, which has a typical Ruddlesden-Popper lattice. The distortion of inorganic $\mathrm{PbI}_{6}$ octahedra results in an increase in the perovskite cavity volume to accommodate the $\mathrm{DMA}^{+}$cation, and the spacing layers of 4 -TFBMA ${ }^{+}$aromatic cations are distributed between the contiguous inorganic sheets. The alternating array forms a $2 \mathrm{D}$ quantum-well configuration that favors the photodetection performance. Crystal-based array detectors of $\mathbf{1}$ exhibit a fascinating detection response, including large detectivity and responsivity and a notable photoresponse time. These findings pave the pathway for exploring new 2D hybrid perovskites, and highlight their promise as candidates for high-performance optoelectronic devices.

Received 30 March 2021; accepted 17 May 2021; published online 16 July 2021

1 Dohner ER, Hoke ET, Karunadasa HI. Self-assembly of broadband white-light emitters. J Am Chem Soc, 2014, 136: 1718-1721

2 Mao L, Wu Y, Stoumpos CC, et al. White-light emission and structural distortion in new corrugated two-dimensional lead bromide perovskites. J Am Chem Soc, 2017, 139: 5210-5215

3 Tan $\mathrm{Z}$, Wu Y, Hong $\mathrm{H}$, et al. Two-dimensional $\left(\mathrm{C}_{4} \mathrm{H}_{9} \mathrm{NH}_{3}\right)_{2} \mathrm{PbBr}_{4}$ perovskite crystals for high-performance photodetector. J Am Chem Soc, 2016, 138: 16612-16615
4 Feng J, Gong C, Gao H, et al. Single-crystalline layered metal-halide perovskite nanowires for ultrasensitive photodetectors. Nat Electron, 2018, 1: 404-410

5 Wang J, Liu Y, Han S, et al. Ultrasensitive polarized-light photodetectors based on $2 \mathrm{D}$ hybrid perovskite ferroelectric crystals with a low detection limit. Sci Bull, 2021, 66: 158-163

6 Han S, Li M, Liu Y, et al. Tailoring of a visible-light-absorbing biaxial ferroelectric towards broadband self-driven photodetection. Nat Commun, 2021, 12: 284

7 Ma Y, Wang J, Liu Y, et al. High performance self-powered photodetection with a low detection limit based on a two-dimensional organometallic perovskite ferroelectric. J Mater Chem C, 2021, 9: 881-887

8 Guo W, Liu X, Han S, et al. Room-temperature ferroelectric material composed of a two-dimensional metal halide double perovskite for $\mathrm{X}$ ray detection. Angew Chem Int Ed, 2020, 59: 13879-13884

9 Zhou F, Abdelwahab I, Leng K, et al. 2D perovskites with giant excitonic optical nonlinearities for high-performance sub-bandgap photodetection. Adv Mater, 2019, 31: 1904155

10 Liu Y, Han S, Wang J, et al. Spacer cation alloying of a homoconformational carboxylate trans isomer to boost in-plane ferroelectricity in a 2D hybrid perovskite. J Am Chem Soc, 2021, 143: 2130-2137

11 Dohner ER, Jaffe A, Bradshaw LR, et al. Intrinsic white-light emission from layered hybrid perovskites. J Am Chem Soc, 2014, 136: 1315413157

12 Smith MD, Watson BL, Dauskardt RH, et al. Broadband emission with a massive Stokes Shift from sulfonium $\mathrm{Pb}-\mathrm{Br}$ hybrids. Chem Mater, 2017, 29: 7083-7087

13 Wong J, Yang K. 2D hybrid halide perovskites: Synthesis, properties, and applications. Sol RRL, 2020, 5: 2000395

14 Shi PP, Lu SQ, Song XJ, et al. Two-dimensional organic-inorganic perovskite ferroelectric semiconductors with fluorinated aromatic spacers. J Am Chem Soc, 2019, 141: 18334-18340

15 Mao L, Stoumpos CC, Kanatzidis MG. Two-dimensional hybrid halide perovskites: Principles and promises. J Am Chem Soc, 2019, 141: 11711190

$16 \mathrm{Wu} \mathrm{Z}$, Ji C, Li L, et al. Alloying $n$-butylamine into $\mathrm{CsPbBr}_{3}$ to give a two-dimensional bilayered perovskite ferroelectric material. Angew Chem Int Ed, 2018, 57: 8140-8143

17 Li L, Sun $\mathrm{Z}$, Wang $\mathrm{P}$, et al. Tailored engineering of an unusual $\left(\mathrm{C}_{4} \mathrm{H}_{9} \mathrm{NH}_{3}\right)_{2}\left(\mathrm{CH}_{3} \mathrm{NH}_{3}\right)_{2} \mathrm{~Pb}_{3} \mathrm{Br}_{10}$ two-dimensional multilayered perovskite ferroelectric for a high-performance photodetector. Angew Chem Int Ed, 2017, 56: 12150-12154

18 Li L, Shang X, Wang S, et al. Bilayered hybrid perovskite ferroelectric with giant two-photon absorption. J Am Chem Soc, 2018, 140: 68066809

19 Wang S, Liu X, Li L, et al. An unprecedented biaxial trilayered hybrid perovskite ferroelectric with directionally tunable photovoltaic effects. J Am Chem Soc, 2019, 141: 7693-7697

20 Goldschmidt VM. Die gesetze der krystallochemie. Naturwissenschaften, 1926, 14: 477-485

21 Guo S, Zhao Y, Bu K, et al. Pressure-suppressed carrier trapping leads to enhanced emission in two-dimensional perovskite $(\mathrm{HA})_{2}(\mathrm{GA}) \mathrm{Pb}_{2} \mathrm{I}_{7}$. Angew Chem Int Ed, 2020, 59: 17533-17539

22 Li X, Fu Y, Pedesseau L, et al. Negative pressure engineering with large cage cations in $2 \mathrm{D}$ halide perovskites causes lattice softening. J Am Chem Soc, 2020, 142: 11486-11496

23 Fu Y, Hautzinger MP, Luo Z, et al. Incorporating large A cations into lead iodide perovskite cages: Relaxed Goldschmidt tolerance factor and impact on exciton-phonon interaction. ACS Cent Sci, 2019, 5: 13771386

24 Katan C, Mercier N, Even J. Quantum and dielectric confinement effects in lower-dimensional hybrid perovskite semiconductors. Chem Rev, 2019, 119: 3140-3192

25 Han S, Liu X, Liu Y, et al. High-temperature antiferroelectric of lead iodide hybrid perovskites. J Am Chem Soc, 2019, 141: 12470-12474

26 Spanopoulos I, Hadar I, Ke W, et al. Uniaxial expansion of the 2D Ruddlesden-Popper perovskite family for improved environmental stability. J Am Chem Soc, 2019, 141: 5518-5534 
27 Chen XG, Song XJ, Zhang ZX, et al. Confinement-driven ferroelectricity in a two-dimensional hybrid lead iodide perovskite. J Am Chem Soc, 2021, 142: 10212-10218

28 Kieslich G, Sun S, Cheetham AK. Solid-state principles applied to organic-inorganic perovskites: New tricks for an old dog. Chem Sci, 2014, 5: 4712-4715

29 Eppel S, Fridman N, Frey G. Amide-templated iodoplumbates: Extending lead-iodide based hybrid semiconductors. Cryst Growth Des, 2015, 15: 4363-4371

30 Li X, Ke W, Traoré B, et al. Two-dimensional Dion-Jacobson hybrid lead iodide perovskites with aromatic diammonium cations. J Am Chem Soc, 2019, 141: 12880-12890

$31 \mathrm{Xu} \mathrm{Z}, \mathrm{Lu} \mathrm{D}$, Liu F, et al. Phase distribution and carrier dynamics in multiple-ring aromatic spacer-based two-dimensional RuddlesdenPopper perovskite solar cells. ACS Nano, 2020, 14: 4871-4881

32 Rodríguez-Romero J, Hames BC, Galar P, et al. Tuning optical/electrical properties of $2 \mathrm{D} / 3 \mathrm{D}$ perovskite by the inclusion of aromatic cation. Phys Chem Chem Phys, 2018, 20: 30189-30199

33 Liao Y, Liu H, Zhou W, et al. Highly oriented low-dimensional tin halide perovskites with enhanced stability and photovoltaic performance. J Am Chem Soc, 2017, 139: 6693-6699

34 Tsai H, Nie W, Blancon JC, et al. High-efficiency two-dimensional Ruddlesden-Popper perovskite solar cells. Nature, 2016, 536: 312-316

35 Zhang S, Yi C, Wang N, et al. Efficient red perovskite light-emitting diodes based on solution-processed multiple quantum wells. Adv Mater, 2017, 29: 1606600

36 Stoumpos CC, Cao DH, Clark DJ, et al. Ruddlesden-Popper hybrid lead iodide perovskite 2D homologous semiconductors. Chem Mater, 2016, 28: $2852-2867$

$37 \mathrm{Xu}$ Z, Li Y, Liu X, et al. Highly sensitive and ultrafast responding array photodetector based on a newly tailored 2D lead iodide perovskite crystal. Adv Opt Mater, 2019, 7: 1900308

38 Liang M, Lin W, Lan Z, et al. Electronic structure and trap states of two-dimensional Ruddlesden-Popper perovskites with the relaxed Goldschmidt tolerance factor. ACS Appl Electron Mater, 2020, 2: 14021412

39 Traore B, Pedesseau L, Assam L, et al. Composite nature of layered hybrid perovskites: Assessment on quantum and dielectric confinements and band alignment. ACS Nano, 2018, 12: 3321-3332

40 Yang T, Li Y, Han S, et al. Exploiting two-dimensional hybrid perovskites incorporating secondary amines for high-performance array photodetection. J Mater Chem C, 2020, 8: 12848-12853

41 Qian L, Sun Y, Sun M, et al. 2D perovskite microsheets for highperformance photodetectors. J Mater Chem C, 2019, 7: 5353-5358

42 Wang J, Li J, Lan S, et al. Controllable growth of centimeter-sized 2D perovskite heterostructures for highly narrow dual-band photodetectors. ACS Nano, 2019, 13: 5473-5484

43 Ji C, Wang $\mathrm{P}, \mathrm{Wu} \mathrm{Z}$, et al. Inch-size single crystal of a lead-free organicinorganic hybrid perovskite for high-performance photodetector. Adv Funct Mater, 2018, 28: 1705467

44 Shen L, Fang Y, Wang D, et al. A self-powered, sub-nanosecondresponse solution-processed hybrid perovskite photodetector for timeresolved photoluminescence-lifetime detection. Adv Mater, 2016, 28: 10794-10800

45 Han S, Wang $\mathrm{P}$, Zhang J, et al. Exploring a polar two-dimensional multi-layered hybrid perovskite of $\left(\mathrm{C}_{5} \mathrm{H}_{11} \mathrm{NH}_{3}\right)_{2}\left(\mathrm{CH}_{3} \mathrm{NH}_{3}\right) \mathrm{Pb}_{2} \mathrm{I}_{7}$ for ultrafast-responding photodetection. Laser Photonics Rev, 2018, 12: 1800060

46 Wang L, Jie J, Shao Z, et al. $\mathrm{MoS}_{2} / \mathrm{Si}$ heterojunction with vertically standing layered structure for ultrafast, high-detectivity, self-driven visible-near infrared photodetectors. Adv Funct Mater, 2015, 25: 29102919

47 Han Q, Bae SH, Sun P, et al. Single crystal formamidinium lead iodide $\left(\mathrm{FAPbI}_{3}\right)$ : Insight into the structural, optical, and electrical properties. Adv Mater, 2016, 28: 2253-2258

Acknowledgements This work was supported by the National Natural Science Foundation of China (21875251, 21833010, 21525104, 22075285 and
21921001), the Key Research Program of Frontier Sciences of the Chinese Academy of Sciences (ZDBS-LY-SLH024), Fujian Science \& Technology Innovation Laboratory for Optoelectronic Information of China (2021ZR126), the Natural Science Foundation of Fujian Province (2018H0047 and 2020J01112), the Strategic Priority Research Program of the Chinese Academy of Sciences (XDB20010200), and the Youth Innovation Promotion of the Chinese Academy of Sciences (2019301 and 2020307).

Author contributions Sun $\mathrm{Z}$ contributed to the conception of the research. Luo J provided suggestions for the research. Guo W performed the experiments and wrote the manuscript. Liu Y, Wang J, Xu H and Ma Y participated in part of the experiments. Liu $\mathrm{X}$ and Han $\mathrm{S}$ assisted with the experimental analysis. Chen $\mathrm{H}$ assisted in the preparation of array detector. All authors discussed the results and reviewed the manuscript.

Conflict of interest The authors declare that they have no conflict of interest.

Supplementary information Supporting data are available in the online version of the paper.

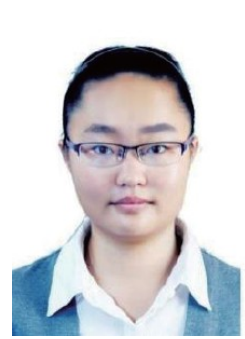

Wuqian Guo received her bachelor's degree from Qingdao University in 2018. She is currently a master degree candidate in inorganic chemistry at Fujian Institute of Research on the Structure of Matter, the Chinese Academy of Sciences (CAS) under the supervision of Prof. Zhihua Sun. Her research interest is the synthesis and characterization of metal-halide ferroelectrics and their optoelectronic properties.

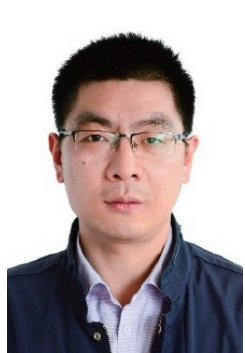

Zhihua Sun received his PhD degree from Shandong University in 2010, and then joined Fujian Institute of Research on the Structure of Matter, CAS. He is a professor of inorganic chemistry at present, and his current research interest focuses on the exploration of new photoactive ferroelectrics and their optoelectronic applications.

\section{合理组装混合阳离子增强金属卤素钙铁矿晶体阵列 光电探测性能}

郭吴倩 ${ }^{1,2}$, 陈怀喜 ${ }^{1}$, 刘希涛 ${ }^{1}$, 马钰 ${ }^{1}$ ，王家棋 ${ }^{1}$, 刘 ${ }^{1,2}$, 韩世国 ${ }^{1,2}$, 徐豪杰 ${ }^{1,2}$, 罗军华 ${ }^{1}$, 孙志华 $1,3^{*}$

摘要 二维Ruddlesden-Popper型杂化钲钛矿 $\left(\mathrm{A}^{\prime}\right)_{2}(\mathrm{~A})_{n-1} \mathrm{M}_{n} \mathrm{X}_{3 n+1}$ 表现出 独特的物理特性与结构兼容性, 已经发展成为光电材料的强有力候选 者, 其无机组分与有机组分的准确调控为优化材料性能提供了广阔空 间. 到目前为止，将大尺寸有机基元作为 $\mathrm{A}$ 位离子占据钻钛矿空腔仍是一 项挑战, 形成此类结构的二维多层钲钛矿材料非常稀少. 鉴于此, 我们将仲 胺和芳香胺作为混合阳离子，利用复合阳离子自组装方法成功制备了结 构新颖的Ruddlesden-Popper型钲钛矿 (4-TFBMA) 2 (DMA) $\mathrm{Pb}_{2} \mathrm{I}_{7}$ ，其中 4 TFBMA为4-(三氟甲基)苠胺, DMA为二甲胺. 该化合物具有典型的双 层钙钛矿结构, DMA作为 $\mathrm{A}$ 位阳离子处于骨架空腔内, 突破容忍因子制 约; 无机骨架层与间隔阳离子 4-TFBMA层交替排列产生量子阱. 以高质 量晶体为基础组装的阵列探测器表现出优异的面内光电性能, 如探测 率高、响应度大、暗电流低和响应速率快等, 性能参数可以媲美二维 无机材料. 综上, 该工作为设计合成新颖二维钲钛矿化合物及实现高效 光电探测性能提供了重要参考. 